\title{
A new initiative in scientific publishing: Arkivoc: a hard copy journal of organic chemistry freely electronically accessible to authors, librarians, and readers
}

\author{
Alan R. Katritzky, ${ }^{*}$ C. Dennis Hall, and Eric F.V. Scriven \\ Department of Chemistry, University of Florida, P.O.Box 117200, Gainesville, \\ FL 32611-7200, USA \\ E-mail: katritzky@chem.ufl.edu
}

\section{Background}

Arkivoc (Archive for Organic Chemistry) was conceived in an attempt to alleviate the following two adverse trends in the practice and publication of organic chemistry, which are particularly acute in countries of the second and third world:

1. The increasing difficulty for researchers in accessing the primary chemical literature because of the increasing cost of journals. The cost of some of the leading journals of organic chemistry are given in Table 1. In Western Europe and North America, libraries face severe difficulties with their budgets; in developing countries the situation is catastrophic.

2. Increasing difficulties for authors to publish their work in journals that are widely available. The pressure on library budgets has recently led to the disappearance (often by amalgamation) of many second rank (and some first rank!) journals. The amalgamated journals claim to be accepting only the best, most novel research that is carried out. Sound work is now often published in a third rank journal (e.g. a university journal with low international availability), in a thesis or sometimes not at all.

\section{Strategy}

The not-for-profit ARKAT USA Inc. Foundation was created in an attempt to address points 1 and 2 simultaneously. Since January 2000, we have published and circulated on the Internet a new, freely accessible journal: Arkivoc. The cost of publishing Arkivoc on the web has been met from an initial donation, from profits made from the Florida Heterocyclic Conferences (Organized by ARKAT USA and held annually since 2000) and above all by unpaid help from many persons. We are now soliciting donations and sponsorships: ARKAT USA Inc. is recognized as a charity by the US. We sell hardcopy issues of the journal at cost as discussed later, but this does not affect the full and free availability of the electronic version. 


\section{Arkivoc: submission and processing of manuscripts}

All correspondence is handled electronically. We have developed and continuously review a set of "Instructions for Authors" that covers research papers, reviews and accounts. Research papers require a full report of experimental work including the complete characterization of all new compounds. Communications without experimental details are not normally accepted. Reviews, as their name implies, involve thorough literature coverage of an important contemporary topic, whereas an "Account” describes recent progress in a topic or technique within the authors' expertise without requiring a comprehensive literature review. Templates are available for "Full Papers" or “Accounts and Reviews" and authors are encouraged to use these as a means of expediting publication. All manuscripts are forwarded electronically either to our Coordinating Editor, A. John Boulton or directly to Arkivoc (detailed instructions are available on the web at www.arkat-usa.org). Dedicated manuscripts for commemorative issues are passed directly to a Scientific Editor appointed by an Arkivoc panel (Charles Rees, Dennis Hall, and Eric Scriven); Victor Zhdankin deals with accounts and reviews other than for Commemorative Issues. Scientific Editors for manuscripts destined for General Issues are appointed by John Boulton, on a rotating basis. Referees are assigned by John Boulton, Gordon Gribble, or Charles Rees taking into account the author's suggestions.

Ave Sarapuu and her team in Estonia effectively form the hub of the whole web publishing operation. Papers sent directly to Arkivoc arrive on her desk and those submitted to John Boulton are also forwarded to Ave, who remain in touch throughout. Ave writes the letters of invitation to the referees appointed by the referee selectors and monitors progress of the papers through the refereeing system. She updates "Manuscripts in the hands of Scientific Editors" on a monthly basis, formats the monthly Newsletter with inputs of news from (ARK, CDH and EFVS) and statistics. Ave also updates the Editorial Board of Referees database either by removing names of referees who have resigned or adding names recommended by members of the Steering Committee. The corresponding author is informed of the name of the Scientific Editor. The manuscript is sent to the Referees who are asked to send their reports directly to the Scientific Editor. The Scientific Editor is sent the MS and the names of the Referees: if reports are not received within two weeks, our system automatically reminds the Referee. After receipt of the Referees' reports, the Scientific Editor can directly accept or reject the paper. Normally, the Scientific Editor will communicate the Referees' reports (anonymously) to the author who will be asked to modify the paper if necessary. At any time the Scientific Editor may correspond further with the original or additional Referees, or with the Technical Editor.

At present, our Editorial Board of Referees consists of 488 scientists from 59 countries covering six continents. We maintain contact with Editorial Board Members by a monthly Newsletter (Editor C. Dennis Hall) giving the Graphical Abstracts of all manuscripts published in the past month and also items of news.

Arkivoc now has eleven Scientific Editors: 5 in Europe (Mikael Begtrup, Christopher Ramsden, Joachim Schantl, Chris Stevens, and Anthony Waring), 5 in the USA (Paul Krapcho, Alan Marchand, Ramaiah Muthyala, Kenneth Turnbull, and Viktor Zhdankin), and 1 in India (H. Ila). The Web Publishing Editor is Eric Scriven; Ramiah Murugan and Angela Sherman are our Technical 
Editors.

Accepted papers are forwarded by the Scientific Editors to Eric Scriven the Web Publishing Editor in Gainesville, Florida where they are given a uniform appearance and prepared for online display and search. HTML and PDF format manuscripts are prepared for easy viewing, downloading, and printing. John Aanonson, our Website Auditor, makes regular weekly checks for accuracy and consistency within the reports.

\section{Electronic/hardcopy publication of Arkivoc}

Issues of Arkivoc are released onto the web site electronically as soon as they are ready. The electronically released issues are precisely formatted for convenient downloading and binding; thus each issue has an appropriate cover page, title page and contents page. There are no restrictions on (or charges for) downloading individual papers or complete issues of Arkivoc for scientific research purposes, for distribution throughout the downloading organization, or for binding and placing them in a library. However, any reproduction of Arkivoc for sale or for transfer to a commercial organization requires permission from the ARKAT USA Inc. as publisher.

For the convenience of organizations (or individuals) who prefer to receive hardcopy journal issues already bound, these are available, usually for \$20 per issue. Copies may be purchased either directly from www.amazon.com or through www.arkat-usa.org under "Enter Arkivoc." For the years 2000 through 2006, hard copies of most issues are already available as of January 1, 2006 from Amazon. For 2007 and subsequent years, we plan to provide these in hard copy format issues shortly after each issue is closed: this operation is guided by Eric Scriven, Dennis Hall, Gala Vakulenko and Sasha Kulshyn.

\section{Scientific scope of Arkivoc}

Arkivoc accepts submissions dealing with all branches of organic chemistry, including physical organic, bioorganic and organic materials chemistry. The prime criteria for acceptance of manuscripts are originality and sound science, including proper characterization of all compounds described (for detailed instructions see web).

An important objective of Arkivoc is to ensure the permanent archival availability of organic chemistry research results worldwide. Because of our cost-free availability, Arkivoc offers potentially wider dissemination of organic chemical results than existing journals. Arkivoc, which has no page charges or costs for authors, offers equal opportunities for chemists worldwide to make their results available to the widest possible audience. Arkivoc is included in the "Lockss" scheme organized by Stanford University by which journals are archived permanently in prominent libraries around the world (see lockss.stanford.edu).

\section{Commemorative and regional issues of Arkivoc}

A secondary objective of Arkivoc is to provide an opportunity to recognize the achievements of chemists by means of Commemorative Issues. Such commemorative issues are well-known, but the chemists so honored have, until now, tended either to come from developed countries or to have 
been honored by dedicated issues in journals of relatively low circulation. Arkivoc seeks to honor distinguished organic chemists worldwide, particularly those whose contributions deserve wider recognition. During 2000-2005, Arkivoc honored 59 chemists from 31 countries with commemorative issues. A further 50 chemists are expected to be so honored in 2006-2010.

Regional issues of Arkivoc are devoted to chemistry from specific countries or regions of the world: our first two regional issues have covered organic chemistry in Mexico and the Ukraine. Instructions and procedures for commemorative issues are given on the web. Suggestions for further commemorative issues can be made to Paul Krapcho (pkrapcho@zoo.uvm.edu) or any Scientific Editor or Control Board Member.

\section{Arkivoc: the position in December 2005}

Six years after its creation, substantial progress has been achieved with our journal. The first five volumes published during 2000 to 2004 comprised a total of 67 issues containing 1029 papers, totaling 11,354 pages. The 2005 volume is expected to run to approximately 3000 pages.

Production of the printed version of Arkivoc is proceeding well, and we expect to have all issues for the years 2000 through 2004 (and 2005 as the issues close) in print early in 2006.

It is interesting to compare this growth with the early years of Tetrahedron whose first three years were: 1957 (384 pages for \$17); 1958 (1138 pages for \$51); 1959 (1038 pages for \$51). In 2005 , Tetrahedron offered 10,500 pages for $\$ 14,203$. The cost per page of organic chemistry journals varies enormously (Table 1 ).

Table 1. Prices (in USD for 2005) and Pages Per Annum of Leading Journals in Organic Chemistry

\begin{tabular}{|l|l|l|}
\hline Price in 2005 & $\begin{array}{l}\text { Number of pages } \\
\text { (in 2004) }\end{array}$ & $\begin{array}{l}\text { Cost per page } \\
\text { (in USD) }\end{array}$ \\
\hline$\$ 14,203$ & 10,500 & $\$ 1.35$ \\
\hline$\$ 10,345$ & 9,726 & $\$ 1.06$ \\
\hline$\$ 3,298$ & 4,249 & $\$ 0.78$ \\
\hline$\$ 2,974$ & 4,743 & $\$ 0.63$ \\
\hline$\$ 1,740$ & 2,794 & $\$ 0.62$ \\
\hline$\$ 2,970$ & 5,067 & $\$ 0.59$ \\
\hline$\$ 1,222$ & 2,127 & $\$ 0.57$ \\
\hline$\$ 2,011$ & 9,491 & $\$ 0.21$ \\
\hline
\end{tabular}

Notes: Prices reflect costs for year 2005 in countries other than that of the producer for an institutional subscription. In making price comparisons, the different sizes of pages and densities of printing need to be taken into consideration; this has not been done. 


\section{Arkivoc: indexing and abstracting}

Each issue of Arkivoc carries graphical abstracts of all papers in that issue. The text and structures in Arkivoc are searchable electronically using authors' names and keywords. Chemical Abstracts has included Arkivoc regularly since 2002. In June 2005 CAS decided to include Arkivoc in their most important group designated "Core journals" and consequently the "Table of contents" for each issue will in future appear on the CAS web site.

\section{Policy and direction of ARKAT USA}

The ARKAT USA Inc. Foundation is managed by a Board of Directors, in accordance with goals and objectives set out in its charter.

The Foundation exists to help scientists in general and organic chemists in particular, throughout the world and particularly in developing countries. Its activities, in addition to publishing Arkivoc, include the organization of the Florida Heterocyclic Chemistry conferences: FloHET-1 through 6 were held highly successfully at the University of Florida each March 2000 through 2005. FloHET 7 is planned for March 2006. In the future we hope to publish useful reference materials for practicing chemists on the ARKAT USA website.

Day-to-day operations are overseen by the ARKAT/Arkivoc/FloHET Steering Committee: A. John Aanonson, A. John Boulton, C. Dennis Hall (secretary), Alan R. Katritzky (Chair), Christopher A. Ramsden, Charles W. Rees, and Eric F. V. Scriven.

Arkivoc has its own Control Board (Chair: Charles W. Rees) consisting of the Coordinating, Scientific, Technical, and Publishing Editors, Referee Assignors, Website Auditor, and Steering Committee Chair. Joint meetings of the ARKAT/Arkivoc/FloHET Steering Committee and Arkivoc Control Board Members take place each March at the FloHET Conference.

The inception of ARKAT and Arkivoc has been made possible by the unpaid efforts of the ARKAT USA Trustees and the Arkivoc Editors and Referees, until now largely on a self-supporting basis. We believe the position should be consolidated to create a permanent on-going organization for the benefit both of chemistry and of humanity worldwide. 